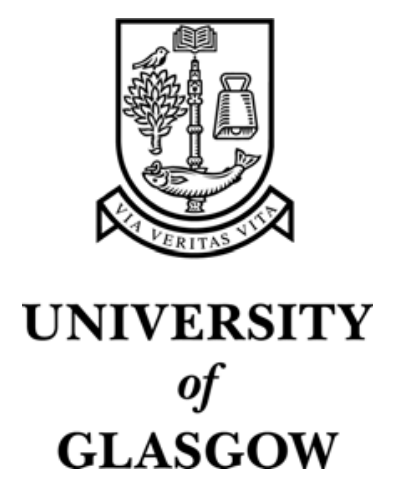

Popescu, M. and Miller, T.J.E. and McGilp, M.I. and Strappazzon, G. and Trivillin, N. and Santarossa, R. (2006) Torque behavior of one-phase permanent magnet AC motor. IEEE Transactions on Energy Conversions 21(1):pp. 19-26.

http://eprints.gla.ac.uk/archive/00002834/ 


\title{
Torque Behavior of One-Phase Permanent-Magnet AC Motor
}

\author{
Mircea Popescu, Senior Member, IEEE, T. J. E. Miller, Fellow, IEEE, Malcolm I. McGilp, Giovanni Strappazzon, \\ Nicola Trivillin, and Roberto Santarossa
}

\begin{abstract}
This paper presents a detailed comparative study of two starting and running methods for a single-phase permanent magnet synchronous motor, equipped with a squirrel-cage rotor. The analysis of the motor performance is realized for a pulse width modulated (PWM) inverter fed motor and for a capacitor-start, capacitor-run motor. The developed approach may be extended to any 1-phase ac motor-induction, synchronous reluctance or synchronous permanent magnet.
\end{abstract}

Index Terms-Capacitor motor, permanent magnet motor, torque.

\section{NOMENCLATURE}

\begin{tabular}{|c|c|}
\hline$v_{\mathrm{s}}$ & Main supply voltage instantaneous value. \\
\hline$v_{\mathrm{m}, \mathrm{a}}$ & $\begin{array}{l}\text { Main/auxiliary voltage components instanta- } \\
\text { neous value. }\end{array}$ \\
\hline$i_{\mathrm{m}, \mathrm{a}}$ & $\begin{array}{l}\text { Main/auxiliary current components instanta- } \\
\text { neous value. }\end{array}$ \\
\hline$v_{\mathrm{d}, \mathrm{q}}$ & $\begin{array}{l}d-q \text { axis voltage components instantaneous } \\
\text { value. }\end{array}$ \\
\hline$i_{\mathrm{d}, \mathrm{q}}$ & $\begin{array}{l}d-q \text { axis current components instantaneous } \\
\text { value. }\end{array}$ \\
\hline$V_{\mathrm{s}}$ & Complex main supply voltage. \\
\hline$\underline{\psi}_{\mathrm{d}, \mathrm{q}}, \underline{I}_{\mathrm{d}, \mathrm{q}}$ & $\begin{array}{l}\text { Complex } d-q \text { axis flux-linkage/current compo- } \\
\text { nents }\end{array}$ \\
\hline$R_{\mathrm{s}}$ & Stator winding resistance. \\
\hline$R_{\mathrm{m}}$ & Stator main winding resistance. \\
\hline$R_{\mathrm{a}}$ & Stator auxiliary winding resistance. \\
\hline$X_{\mathrm{ls}}$ & Stator leakage reactance. \\
\hline$X_{\operatorname{lm}}$ & Stator main leakage reactance. \\
\hline$X_{\text {la }}$ & Stator auxiliary leakage reactance. \\
\hline$\beta$ & Turns ratio (main/aux). \\
\hline$\zeta$ & Shift electrical angle between stator windings. \\
\hline$\theta$ & Rotor angle in electrical degrees. \\
\hline$\phi_{\mathrm{m}, \mathrm{a}}$ & Wire diameter of the main/auxiliary winding. \\
\hline$R_{\mathrm{rd}}, R_{\mathrm{rq}}$ & Rotor resistance for $d-q$ axis. \\
\hline$X_{\mathrm{lrd}}, X_{\mathrm{lrq}}$ & Rotor leakage reactance for $d-q$ axis. \\
\hline$X_{\mathrm{md}}, X_{\mathrm{mq}}$ & Magnetization reactance for $d-q$ axis. \\
\hline$X_{\mathrm{d}}, X_{\mathrm{q}}$ & Synchronous reactance for $d-q$ axis. \\
\hline$C$ & Capacitance value. \\
\hline$m, P$ & Phases and pole numbers. \\
\hline 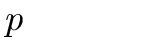 & Time derivative operator. \\
\hline
\end{tabular}

Manuscript received March 28, 2003; revised February 12, 2004. Paper no. TEC-00070-2003.

M. Popescu, M. I. McGilp, and T. J. E. Miller are with SPEED Laboratory, University of Glasgow, Glasgow G12 8LT, U.K. (e-mail: mirceap@ ieee.org).

G. Strappazzon, N. Trivillin, and R. Santarossa are with ACC Compressors, Pordenone 33170, Italy.

Digital Object Identifier 10.1109/TEC.2005.845450

$\begin{array}{ll}\omega & \begin{array}{l}\text { Synchronous angular velocity (in electrical ra- } \\ \text { dians per second). }\end{array} \\ \omega_{\mathrm{r}} & \begin{array}{l}\text { Rotor angular velocity (in electrical radians per } \\ \text { second). } \\ \end{array} \\ \omega_{\mathrm{k}} & \begin{array}{l}k \text { th harmonic angular velocity (in electrical ra- } \\ \text { dians per second). }\end{array} \\ E_{0} & \text { Open-circuit induced voltage (in voltage root } \\ & \text { mean square) } \\ T_{\mathrm{e}} & \text { Electromagnetic torque. } \\ T_{\mathrm{m}} & \text { Magnet braking torque. } \\ T_{\mathrm{rel}} & \text { Reluctance torque. } \\ T_{\mathrm{cage}} & \text { Cage rotor torque. } \\ T_{(\text {avg) }} & \text { Symmetrical components cage rotor torque. }\end{array}$

\section{INTRODUCTION}

$\mathbf{T}$ HE single-phase version of the permanent magnet ac motor is mainly employed in home appliances, such as refrigerator compressors. Once in synchronous operation a permanent magnet will exhibit a higher efficiency compared to its equivalent induction motor (i.e., same rated power, frequency and pole pairs). This is due to the magnets presence that may increase (when properly designed) the electromagnetic torque for the same input power. However, the magnets effects have a strong drawback.

The excitation realized with permanent magnets cannot be switched off. Hence, it will considerably affect the starting capabilities of such motors. The stator-induced currents due to the magnets movement will close through the supply impedance and will determine the so-called magnet braking torque [1], [3]. Also, the torque oscillations during the starting transient are much higher than for an induction motor or a wound field synchronous motor equipped with a cage rotor. Consequently, the starting performance of a permanent magnet ac motors represents one of the key points when designing the assembly electric motor-electric drives. Because in its single-phase version the ac permanent magnet motor is characterized by asymmetries on both stator (unbalanced windings) and rotor (reluctance effect, unsymmetrical rotor cage) the starting operation stands for a challenging task.

The inverter-fed motor associated with the current-speed control loops drive represents the complex and costly solution. Even though such a motor-drive configuration would ensure a complete control over the motor electromagnetic performance (torque, speed, current), there are several possible applications where a fixed operation speed is requested and furthermore the cost criterion represents one of the main issues in optimizing the assembly electrical motor drive. 
The cheaper solution for starting an ac interior permanent magnet motor is achieved by the usage of a rotor equipped with a squirrel cage, similarly to an induction motor. If the $m$ phase version of the ac permanent magnet motor equipped with a cage rotor can be started through a direct connections to the ac mains, the 1-phase version requests specific starting devices to be connected. The most common configuration would be to use two fixed value capacitors for the implementation of a start-capacitor, run-capacitor motor solution. The other possible solution is to supply the motor with 2-phase balanced voltages. This task is achievable through different configurations in a similar way to those already developed for the 1-phase induction motor case [7], [8], [11]-[13]. Generically, we can classify the configuration of the 1-phase ac permanent magnet motor according to the supply voltage system: unbalanced and balanced motors.

This paper investigates two starting and running configurations for a single-phase permanent magnet ac motor equipped with cage rotor:

- unbalanced case - a fixed value capacitor start, capacitor run motor;

- balanced case-a PWM voltage inverter fed motor equipped with cage rotor (open current-speed loop).

This paper investigates two starting configurations for a single-phase permanent magnet ac motor: a capacitor start, capacitor run motor and a PWM inverter supplied motor. Fig. 1 illustrates the flux paths in a cross-section of a one-phase permanent magnet motor under load.

The subject of the analysis for the single-phase starting performance is a single-phase permanent magnet ac motor, $50 \mathrm{~Hz}$, two-pole motor with concentric windings. The rotor consists of an aluminum rotor cage, with interior ferrite magnets.

\section{MATHEMATICAL ModEL}

\section{A. General d-q Axis Model}

Analysis of an $m$-phase balanced permanent magnet ac motor with salient-pole rotor is carried out using the voltage equations in the rotor reference frame under the following assumptions:

- No saturation effect, i.e., motor inductance is not affected by current level;

- Negligible spatial m.m.f. harmonics, i.e., the stator windings and rotor magnets are arranged to produce sinusoidal m.m.f. airgap distribution;

- The effects of stator slots may be neglected;

- There is no fringing of the magnet field;

- The magnetic field intensity is constant and radially directed across the air-gap, such that the permanent magnet may be equivalent to a super conducting winding (e), where the equivalent current is always constant with $i_{\mathrm{e}}=E_{0} / X_{\mathrm{md}}$

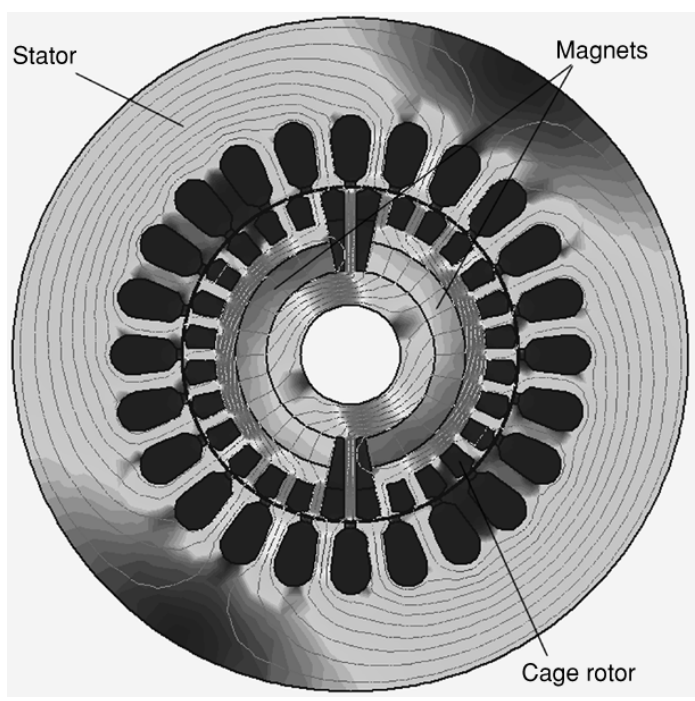

Fig. 1. Cross-section of a one-phase permanent magnet ac motor with flux lines plot when motor operates under load.

- Eddy current and hysteresis effects are negligible.

The rotor cage is substituted with two equivalent sinusoidally distributed windings ( $r d$ and $r q$ ), with magnetic axes shifted by 90 electrical degrees. The voltage equations are expressed through the following matrix equation, shown at the bottom of the page. The following expressions compute the instantaneous electromagnetic torque and its components (reluctance, cage and alignment (i.e., excitation):

$$
\begin{aligned}
T_{\mathrm{e}}= & \frac{m P}{2 \omega} \cdot\left[\left(X_{\mathrm{md}}-X_{\mathrm{mq}}\right) i_{\mathrm{d}} i_{\mathrm{q}}\right. \\
& \left.+\left(X_{\mathrm{md}} i_{\mathrm{dr}} i_{\mathrm{q}}-X_{\mathrm{mq}} i_{\mathrm{qr}} i_{\mathrm{d}}\right)+X_{\mathrm{md}} i_{\mathrm{e}} i_{\mathrm{q}}\right] \\
= & T_{\mathrm{rel}}+T_{\mathrm{cage}}+T_{\mathrm{m}} \\
T_{\mathrm{rel}}= & \frac{m P}{2 \omega}\left(X_{\mathrm{md}}-X_{\mathrm{mq}}\right) i_{\mathrm{d}} i_{\mathrm{q}}=\frac{m P}{2 \omega_{\mathrm{s}}}\left(X_{\mathrm{d}}-X_{\mathrm{q}}\right) i_{\mathrm{d}} i_{\mathrm{q}} \\
T_{\text {cage }}= & \frac{m P}{2 \omega}\left(X_{\mathrm{md}} i_{\mathrm{dr}} i_{\mathrm{q}}-X_{\mathrm{mq}} i_{\mathrm{qr}} i_{\mathrm{d}}\right) \\
T_{\mathrm{m}}= & \frac{m P}{2 \omega} X_{\mathrm{md}} i_{\mathrm{e}} i_{\mathrm{q}}=\frac{m P}{2 \omega} E_{0} i_{\mathrm{q}}
\end{aligned}
$$

The magnet braking torque is produced by the fact that the magnet flux generates currents in the stator windings, and is associated with the loss in the stator circuit resistance. The variation of this torque with speed follows a pattern similar to that in the induction motor, but the per-unit speed takes the place of the slip. The magnet braking torque should not be confused with the synchronous "alignment" torque that arises at synchronous speed, even though the magnet braking torque is still present at synchronous speed and therefore diminishes the output and the efficiency.

$$
\left[\begin{array}{c}
v_{\mathrm{d}} \\
v_{\mathrm{q}} \\
0 \\
0
\end{array}\right]=\left[\begin{array}{ccccc}
R_{\mathrm{s}}+\frac{p}{\omega} X_{\mathrm{d}} & -\frac{\omega_{\mathrm{r}}}{\omega} X_{\mathrm{q}} & 0 & \frac{p}{\omega} X_{\mathrm{md}} & -\frac{\omega_{\mathrm{r}}}{\omega} X_{\mathrm{md}} \\
\frac{\omega_{\mathrm{r}}}{\omega} X_{\mathrm{d}} & R_{\mathrm{s}}+\frac{p}{\omega} X_{\mathrm{q}} & \frac{\omega_{\mathrm{r}}}{\omega} X_{\mathrm{md}} & \frac{\omega_{\mathrm{r}}}{\omega} X_{\mathrm{mq}} & \frac{p}{\omega} X_{\mathrm{mq}} \\
\frac{\underline{p}}{\omega} X_{\mathrm{md}} & 0 & 0 & R_{\mathrm{rd}}+\frac{p}{\omega} X_{\mathrm{lrd}} & 0 \\
0 & \frac{p}{\omega} X_{\mathrm{mq}} & 0 & 0 & R_{\mathrm{rq}}+\frac{p}{\omega} X_{\mathrm{lrq}}
\end{array}\right] \cdot\left[\begin{array}{c}
i_{\mathrm{d}} \\
i_{\mathrm{q}} \\
i_{\mathrm{e}} \\
i_{\mathrm{rd}} \\
i_{\mathrm{rq}}
\end{array}\right]
$$


During starting, the accelerating torque of the permanent magnet ac motor is the average cage torque minus the magnet braking torque and the load torque. The average cage torque is developed by "induction motor action", except that the saliency and the unbalanced stator voltages complicate the analysis and may compromise performance. The magnet alignment torque has a nonzero average value (i.e., averaged over one revolution or electrical cycle) only at synchronous speed. At all other speeds it contributes an oscillatory component of torque. The same is true of the reluctance torque. As the rotor approaches synchronous speed, the screening effect of the cage becomes less, and as the slip is very small, the oscillatory synchronous torques (alignment and reluctance) cause large variations in speed that may impair the ability to synchronize large-inertia loads.

At synchronous speed (steady-state) the time derivative terms become zero. Note that for the case of $E_{0}=0$ we can obtain the equation system for a synchronous reluctance motor. For zero excitation voltage plus the additional condition $X_{\mathrm{d}}=X_{\mathrm{q}}$ (no reluctance effect), the induction motor case can be obtained.

\section{B. Capacitor-Start, Capacitor-Run Motor}

Fig. 2 illustrates the general pattern for the capacitor onephase permanent magnet ac motor. The magnetic axes of the stator windings are usually electrically orthogonal. This way the mutual coupling between stator windings is minimized.

Fig. 3 shows a schematic structure of stator windings connection for a capacitor-start, capacitor run permanent magnet ac motor. This connection is employed for the test motor.

The single-phase permanent magnet ac motor may exhibit asymmetries both on the stator (unbalanced windings and supply voltages) and the rotor (saliency). This makes the classical $d-q$ axes analysis on a certain reference frame impossible, without the assumption that the stator windings have the same copper weight and distribution, i.e., $R_{\mathrm{s}}=R_{\mathrm{m}}=\beta^{2} R_{\mathrm{a}}$, $X_{\mathrm{ls}}=X_{\mathrm{lm}}=\beta^{2} X_{\mathrm{la}}, \phi_{\mathrm{a}}=\beta^{1 / 2} \phi_{\mathrm{m}}$. Torque behavior may be determined using: quasi steady-state analysis [1], steady-state analysis [2], [4] or a dynamic analysis [2].

Quasi steady-state performance may be described with the relations [1]

$$
\begin{aligned}
T_{(\mathrm{avg})+} & =\frac{P}{2} \cdot \operatorname{Re}\left\{\left(\underline{\psi}_{\mathrm{q}+}\right)^{*} \underline{I}_{\mathrm{d}+}-\left(\underline{\psi}_{\mathrm{d}+}\right)^{*} \underline{\mathrm{I}}_{\mathrm{q}+}\right\} \\
T_{(\mathrm{avg})-} & =\frac{P}{2} \cdot \operatorname{Re}\left\{\left(\underline{\psi}_{\mathrm{q}-}\right)^{*} \underline{I}_{\mathrm{d}-}-\left(\underline{\psi}_{\mathrm{d}-}\right)^{*} \underline{I}_{\mathrm{q}-}\right\} \\
T_{\mathrm{m}} & =\frac{P}{2} \cdot \sin (\zeta)\left[\beta \cdot \psi_{\mathrm{dm}} I_{\mathrm{qm}}-\frac{1}{\beta} \cdot \psi_{\mathrm{qm}} I_{\mathrm{dm}}\right] \\
T_{\mathrm{e}} & =T_{(\mathrm{avg})+}+T_{(\mathrm{avg})-}+T_{\mathrm{m}} .
\end{aligned}
$$

For the case of dynamic analysis, the transformed $d-q$ axis voltages and currents are linked to the real values through the relations [2]

$$
\begin{aligned}
& v_{\mathrm{d}}=v_{\mathrm{s}}\left[(1+\cos (\zeta)) \cos (\theta)+\frac{\sin (\zeta)}{\beta} \sin (\theta)\right]-v_{\mathrm{c}} \cos (\theta) \\
& v_{\mathrm{q}}=v_{\mathrm{s}}\left[-(1+\cos (\zeta)) \sin (\theta)+\frac{\sin (\zeta)}{\beta} \cos (\theta)\right]+v_{\mathrm{c}} \sin (\theta)
\end{aligned}
$$

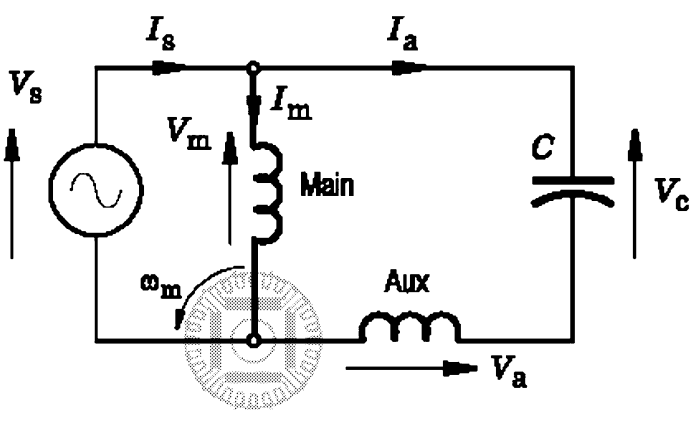

Fig. 2. General structure of the connections for a capacitor one-phase permanent magnet ac motor.

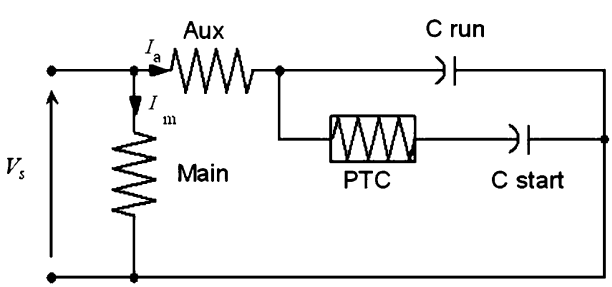

Fig. 3. Schematic structure of the stator windings connection for a capacitor start, capacitor run single-phase permanent magnet ac motor.

$$
\begin{aligned}
& i_{\mathrm{d}}=i_{\mathrm{m}}[\beta \sin (\theta) \sin (\zeta)+\cos (\theta) \cos (\zeta)]+i_{\mathrm{a}} \cos (\theta) \\
& i_{\mathrm{q}}=i_{\mathrm{m}}[\beta \cos (\theta) \sin (\zeta)-\sin (\theta) \cos (\zeta)]-i_{\mathrm{a}} \sin (\theta)
\end{aligned}
$$

The capacitor voltage is a state variable and must be incorporated in the terminal constraints of the permanent magnet ac motor, which are

$$
v_{\mathrm{c}}=\frac{1}{C} \int i_{\mathrm{a}} d t ; \quad v_{\mathrm{m}}=v_{\mathrm{s}} ; \quad v_{\mathrm{a}}=v_{\mathrm{s}}-v_{\mathrm{c}} ; \quad i_{\mathrm{s}}=i_{\mathrm{m}}+i_{\mathrm{a}} .
$$

In steady-state operation, the motor performance can be predicted using the symmetrical components theory [6]. Thus, the positive sequence voltage is characterized by the following average electromagnetic torque components:

$$
T_{\mathrm{e}+}=T_{\mathrm{rel}}+T_{\mathrm{m}} .
$$

For a one-phase permanent magnet motor, the positive and negative sequence voltages $V_{+}, V_{-}$depends on the equivalent positive and negative impedances $\underline{Z}_{+}, \underline{Z}_{-}$.

If the positive sequence impedance $\underline{Z}_{+}$is variable with the load angle $\delta$, and determined through an iterative process, the negative sequence impedance may be computed as the average between $d$ and $q$ axis impedance [1].

The complete analysis of the steady-state performance for a 1-phase permanent magnet motor includes the negative sequence voltage contribution. The corresponding torque is computed as a ratio between the electromagnetic power and the synchronous angular velocity

$$
T_{\mathrm{e}-}=\frac{P}{2 \omega} \cdot\left[\operatorname{Re}\left(\underline{V}_{-} \cdot\left(\underline{I}_{-}\right)^{*}\right)-R_{\mathrm{s}} \cdot\left|\underline{I}_{-}\right|^{2}\right]
$$

where the negative sequence current is computed as

$$
\underline{I}_{-}=\frac{\underline{V}_{-}}{\underline{Z}_{-}} .
$$


The total average electromagnetic torque at steady-state operation will be

$$
T_{\mathrm{e}}=T_{\mathrm{e}+}+T_{\mathrm{e}-}
$$

At synchronous speed, the interaction between the induced currents by the permanents magnets movement and the positive and negative sequence currents will determine two average electromagnetic pulsating torque that very with $2 f$ and $4 f$ frequency, where $f$ is the fundamental supply frequency [1]. Their peak amplitude can be computed as

$$
\begin{aligned}
T_{(\mathrm{puls})(2 f)}= & \frac{P}{2} \cdot \operatorname{Abs}\left[\left(\underline{\psi}_{\mathrm{q}+}\right) \underline{I}_{\mathrm{d}-}-\left(\underline{\psi}_{\mathrm{d}+}\right) \underline{I}_{\mathrm{q}-}\right] \\
& +\frac{P}{2} \cdot \operatorname{Abs}\left[\left(\underline{\psi}_{\mathrm{q}-}\right) \underline{I}_{\mathrm{d}+}-\left(\underline{\psi}_{\mathrm{d}-}\right) \underline{I}_{\mathrm{q}+}\right] \\
& +\frac{P}{2} \cdot \operatorname{Abs}\left\{\left[\left(\underline{\psi}_{\mathrm{q}-}\right) I_{\mathrm{dm}}+\left(\psi_{\mathrm{qm}}\right) \underline{I}_{\mathrm{d}-}\right]\right. \\
& \left.-\left[\left(\underline{\psi}_{\mathrm{d}-}\right) I_{\mathrm{qm}}+\left(\psi_{\mathrm{dm}}\right) \underline{I}_{\mathrm{q}-}\right]\right\} \\
T_{(\mathrm{puls})(4 f)}= & \frac{P}{2} \cdot \operatorname{Abs}\left[\left(\underline{\psi}_{\mathrm{q}-}\right) \underline{I}_{\mathrm{d}-}-\left(\underline{\psi}_{\mathrm{d}-}\right) \underline{I}_{\mathrm{q}-}\right] .
\end{aligned}
$$

With a proper selection of the capacitor-run and turns ratio values [2], the negative sequence voltage is zero only for one specific load and speed value. Thus the backward revolving field vanishes and the motor operates in a balanced mode. At balanced operation, the negative sequence torque $\left(T_{\mathrm{e}-}\right)$ will be zero. Consequently, the pulsating torques will be eliminated.

\section{PWM Inverter-Fed Motor}

The 1-phase permanent magnet ac motor can operate as a balanced motor, if the supply voltage system is balanced. The analyzed solution in this paper is a PWM inverter fed motor. Through an appropriate control strategy [7], [8] by keeping the stator windings applied voltages de-phased with 90 electrical degrees and with the amplitude ratio equal to the effective turns ratio, the negative sequence voltage is zero.

Fig. 4 shows a schematic structure of a three-phase PWM inverter used to operate the 1-phase permanent magnet motor as a balanced motor. The advantages and drawbacks of this solution when applied to a 1-phase induction motor are analyzed in [8]. The same control strategy pattern was employed for driving the tested 1-phase permanent magnet ac motor.

Quasi steady-state performance may be described with the following relations, considering a balanced supply voltage system [1]:

$$
T_{\mathrm{e}}=T_{(\mathrm{avg})+}+T_{\mathrm{m}} .
$$

As the motor always operates in balanced conditions there are no pulsating torques due to the supply voltage fundamentals. However, the higher order harmonics will determine pulsating torques which vary with $2 \mathrm{kf}$ and $4 \mathrm{kf}$ frequency.

For the case of the dynamic analysis, the transformed $d-q$ axis voltages and currents are linked to the real values through the relations [2]

$$
v_{\mathrm{d}}=v_{\mathrm{m}}\left[\cos (\zeta) \cdot \cos (\theta)+\frac{\sin (\zeta)}{\beta} \cdot \sin (\theta)\right]+v_{\mathrm{a}} \cos (\theta)
$$

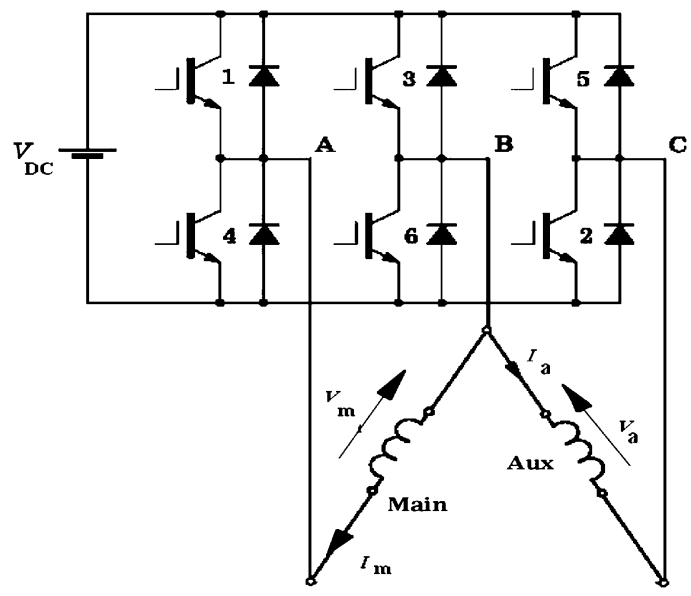

Fig. 4. Schematic structure of the stator windings connection for a PWM-controlled inverter-fed one-phase permanent magnet ac motor.

$$
\begin{aligned}
& v_{\mathrm{q}}=v_{\mathrm{m}}\left[-\cos (\zeta) \cdot \sin (\theta)+\frac{\sin (\zeta)}{\beta} \cdot \cos (\theta)\right]-v_{\mathrm{a}} \sin (\theta) \\
& i_{\mathrm{d}}=i_{\mathrm{m}}[\beta \sin (\theta) \sin (\zeta)+\cos (\theta) \cos (\zeta)]+i_{\mathrm{a}} \cos (\theta) \\
& i_{\mathrm{q}}=i_{\mathrm{m}}[\beta \cos (\theta) \sin (\zeta)-\sin (\theta) \cos (\zeta)]-i_{\mathrm{a}} \sin (\theta) .
\end{aligned}
$$

The supply voltages $v_{\mathrm{m}}$ and $v_{\mathrm{a}}$ are described by the same time variation pattern, a pulse width modulated voltage inverter with $k_{\mathrm{r}}$ rectifier coefficient, displaced in phase with $90^{\circ}$, and their amplitude ratio is equal to the turns ratio $\beta$ [8]

$$
\begin{aligned}
& \left|v_{\mathrm{m}}\right|=\frac{\sqrt{2}}{\pi} \cdot k_{\mathrm{r}} \cdot\left|v_{\mathrm{S}}\right|=\frac{\sqrt{2}}{\pi} \cdot\left|v_{\mathrm{DC}}\right| \\
& \left|v_{\mathrm{a}}\right|=\frac{1}{\beta} \cdot \frac{\sqrt{2}}{\pi} \cdot k_{\mathrm{r}} \cdot\left|v_{\mathrm{s}}\right|=\frac{1}{\beta} \cdot \frac{\sqrt{2}}{\pi} \cdot\left|v_{\mathrm{DC}}\right| .
\end{aligned}
$$

The steady-state performance may be computed with the previous expressions (22)-(28), but considering the harmonic effects and substituting for each $k$ th harmonic

$$
\begin{aligned}
\cos \theta_{k} & =\frac{\omega_{k}}{\omega} \\
\sin \theta_{k} & =j \frac{\omega_{k}}{\omega} .
\end{aligned}
$$

\section{EXPERIMENTAL AND SiMULATION RESULTS}

The experiments were performed on a motor equipped with identical stator windings. As the purpose of this work was to study the torque behavior for different driving methods, the prototype motor was not optimized.

Figs. 5 and 6 show the main winding layout and turns per coil distribution, respectively. The auxiliary winding is shifted with 90 electrical degrees and exhibit the same layout and turns per coil distribution.

First, the starting method was implemented using two selected capacitor values for the capacitor motor connection: $23 \mu \mathrm{F}$ at low speed (starting) and $3 \mu \mathrm{F}$ at high speed (speed $>80-90 \%$ of synchronous speed). The selection criteria were maximum starting torque/current and balanced operation and/or equal current densities in the stator windings [9] at nominal load and synchronous speed. The starting capacitor is connected in series with a positive temperature 


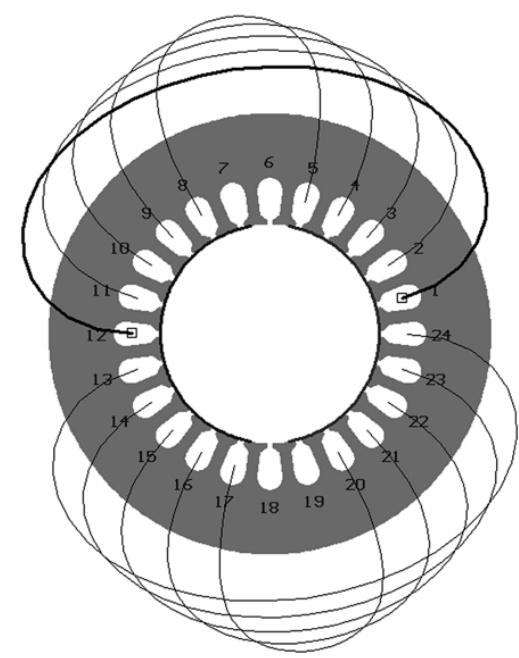

Fig. 5. Stator main winding layout of the test motor.

\begin{tabular}{|c|c|c|c|c|}
\hline Coil & Go & Ret & Span & Turns \\
\hline $\mathbf{1}$ & $\mathbf{1}$ & 12 & 11 & 125 \\
\hline $\mathbf{2}$ & 2 & 11 & 9 & 105 \\
\hline $\mathbf{3}$ & 3 & 10 & 7 & 83 \\
\hline $\mathbf{4}$ & 4 & 9 & 5 & 66 \\
\hline $\mathbf{5}$ & 5 & $\mathbf{8}$ & 3 & 45 \\
\hline $\mathbf{6}$ & 24 & 13 & -11 & 125 \\
\hline $\mathbf{7}$ & 23 & 14 & -9 & 105 \\
\hline $\mathbf{8}$ & 22 & 15 & -7 & 83 \\
\hline $\mathbf{9}$ & 21 & 16 & -5 & 66 \\
\hline $\mathbf{1 0}$ & 20 & 17 & -3 & 45 \\
\hline
\end{tabular}

Fig. 6. Stator main winding distribution of the test motor.

coefficient resistor (PTC). For a complete comparison tests were performed with:

- starting capacitor value equal to $10 \mu \mathrm{F}, 23 \mu \mathrm{F}$, and $40 \mu \mathrm{F}$;

- run capacitor value equal to $3 \mu \mathrm{F}$.

The use of a run capacitor for the synchronous operation of the one-phase permanent magnet motor achieves maximum efficiency for only one load point. Thus, if the load varies (as it does in of refrigerator compressors) a suggested solution would be to use a permanently balanced supply voltage system. This justifies the second analyzed starting method that can be implemented using a two-phase [7] or a three-phase PWM inverter [8]. Experimental data were obtained for the three-phase solution that comprises six MOSFET transistors. The rectifier-inverter assembly used for the second starting method was directly connected to the ac mains $(220 \mathrm{~V}, 50 \mathrm{~Hz})$. Thus, the machine is fed by a sinusoidal modulated voltage waveform had a $50 \mathrm{~Hz}$ frequency and $200 \mathrm{~V} \mathrm{rms}$. The switching frequency for the triangular modulation signal was $5.5 \mathrm{kHz}$. The motor was driven in an open loop at constant frequency. At synchronous speed and variable load the measured output fundamental voltage value was between $150 \mathrm{~V}$ rms and $132 \mathrm{~V}$ rms.

Saturation of the magnetic circuit is particularly complex in this motor type: different sections of the machine saturate independently, causing large and some times time-varying changes in equivalent-circuit parameters such as inductances $X_{\mathrm{d}}$ and $X_{\mathrm{q}}$ and $\operatorname{EMF}\left(E_{0}\right)$. Accordingly two series of finite-element calculations were carried out, one with current only in the $d$-axis and

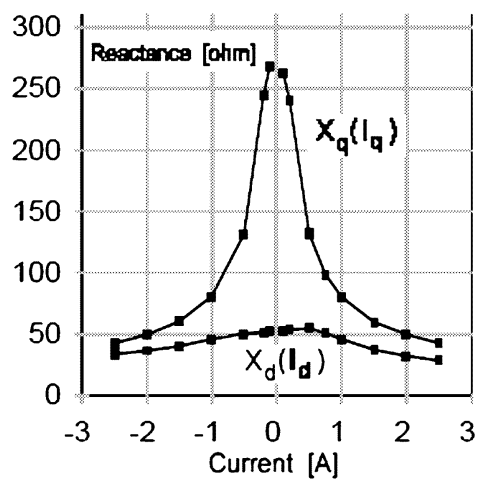

Fig. 7. Variation of $X_{\mathrm{d}}$ versus $I_{\mathrm{d}}$ with $I_{\mathrm{q}}=0$, and of $X_{\mathrm{q}}$ versus $I_{\mathrm{q}}$ with $I_{\mathrm{d}}=0$, calculated using finite element data with constant $E_{0}$.

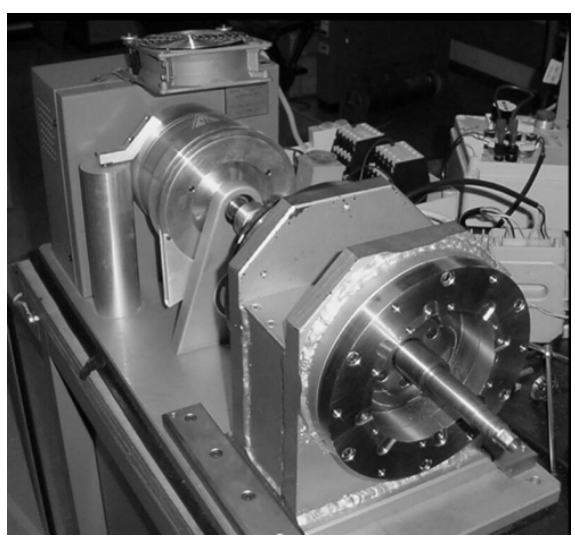

Fig. 8. Test stand settings.

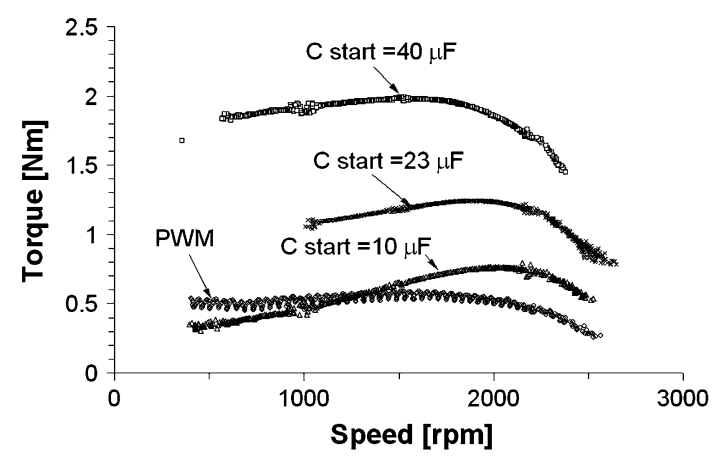

Fig. 9. Experimental torque variation versus speed during starting (capacitor motor-C start and inverter fed motor- PWM).

the other with current only in the q-axis. For each solution, $X_{\mathrm{d}}$ and $X_{\mathrm{q}}$ were obtained as in [14] with a $50 \mathrm{~Hz}$ fundamental frequency. The result is given in Fig. 7, which expresses $X_{\mathrm{d}}$ as a function of $I_{\mathrm{d}}$ with $I_{\mathrm{q}}=0$, and $X_{\mathrm{q}}$ as a function of $I_{\mathrm{q}}$ with $I_{\mathrm{d}}=0$. In all cases it is assumed that $E_{0}$ is constant, as in [1]. Fig. 7 shows a huge variation of 6:1 in $X_{\mathrm{q}}$ and almost 2:1 in $X_{\mathrm{d}}$. The fixed value equivalent circuit parameters are listed in Appendix.

Fig. 8 shows the settings for the test stand and Figs. 9, 11 illustrate the experimental quasisteady state torque vs. speed and RMS current versus speed respectively. An hysteresis brake (coupled with an acquisition and control system) was used to test the motor. The automatic procedure starts running the motor without load, then gradually decreases the speed measuring at 


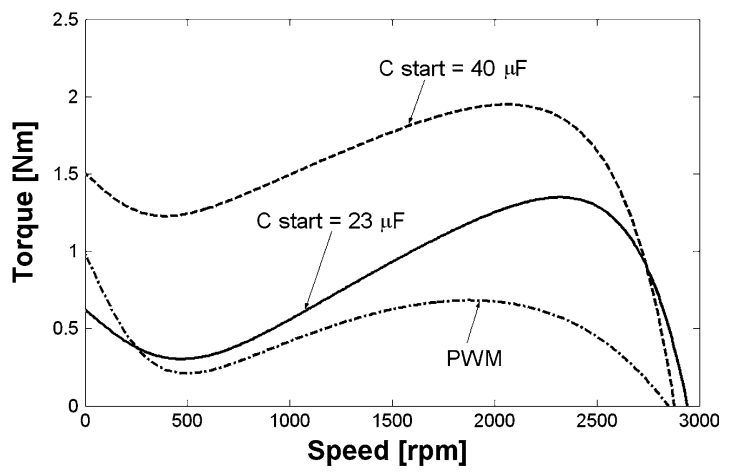

Fig. 10. Computed torque variation versus speed during starting (capacitor motor- $\mathrm{C}$ start and inverter-fed motor-PWM).

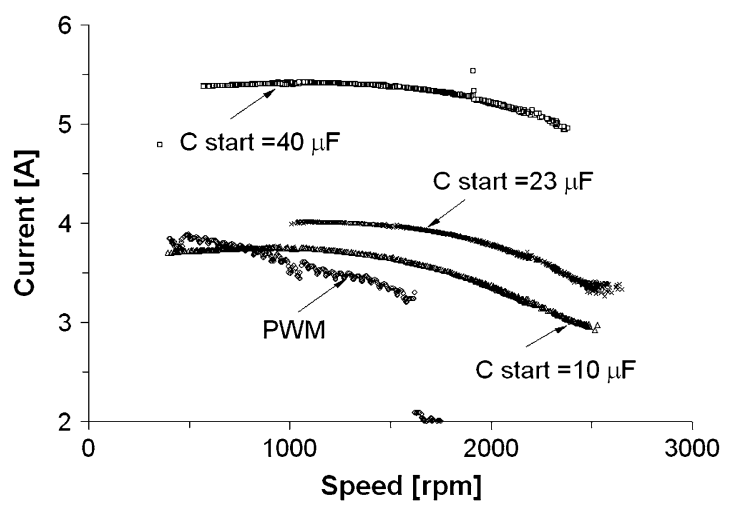

Fig. 11. Experimental current variation versus speed during starting (capacitor motor- $\mathrm{C}$ start and inverter-fed motor-PWM).

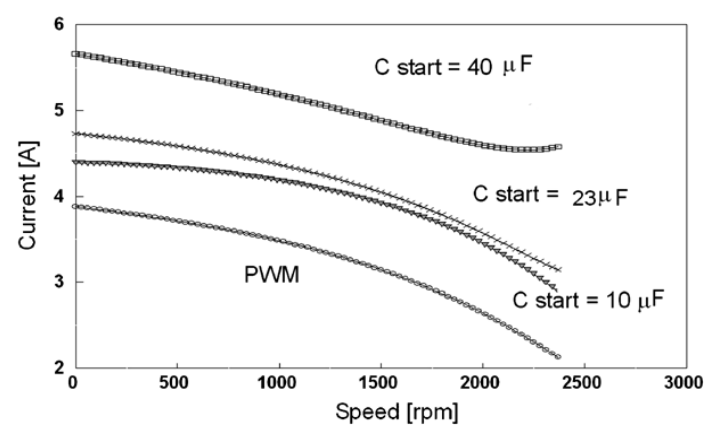

Fig. 12. Computed current variation versus speed during starting (capacitor motor-C start and inverter-fed motor-PWM).

each step the torque and power. The torque experimental data was obtained with a MAGTROL torque transducer.

The experiments were intended to study the torque behavior during starting, synchronization and synchronous operation, for a wide range of capacitance values. The tested motors exhibited large torque oscillations at low speed. This phenomenon makes any measurement for locked rotor or low speed conditions very difficult.

Starting computed results are presented for the quasi steady-state torque (Fig. 10) and RMS current (Fig. 12), transient speed (Fig. 13), currents (Figs. 14 and 15) and torque (Figs. 16 and 17). In Figs. 11 and 12 for the capacitor motor the total input current is presented, whilst for the inverter fed motor the phase current is given. The dynamic computation for the capacitor motor was implemented using a capacitor-start

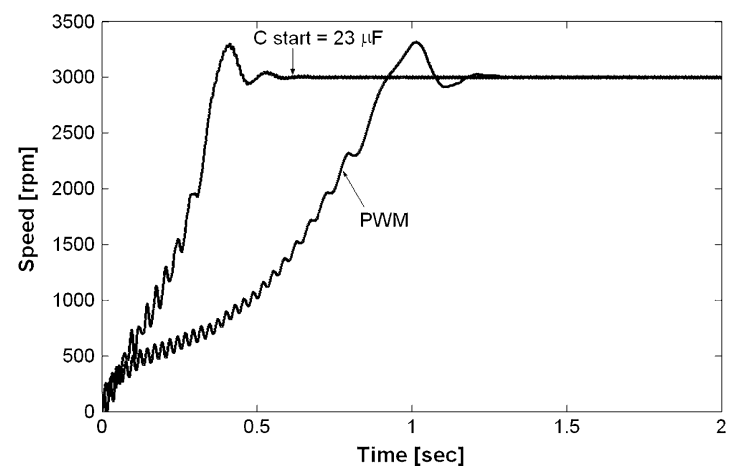

Fig. 13. Computed speed versus time variation during starting (capacitor motor- $\mathrm{C}$ start and inverter-fed motor-PWM).

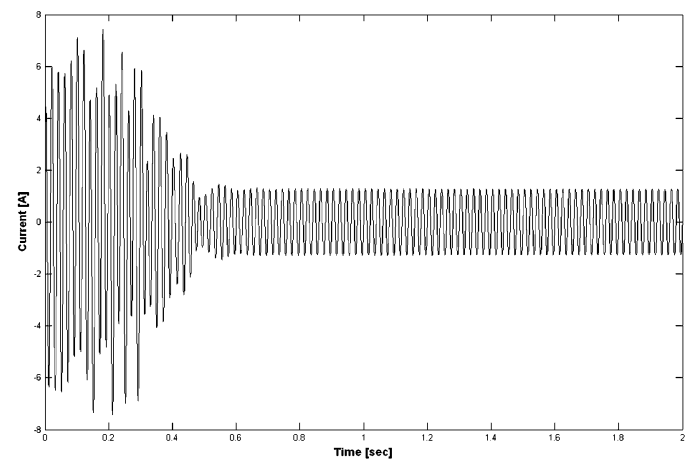

Fig. 14. Computed current versus time variation for capacitor motor during starting $(\mathrm{C}$ start $=23 \mu \mathrm{F}, \mathrm{C}$ run $=3 \mu \mathrm{F})$.

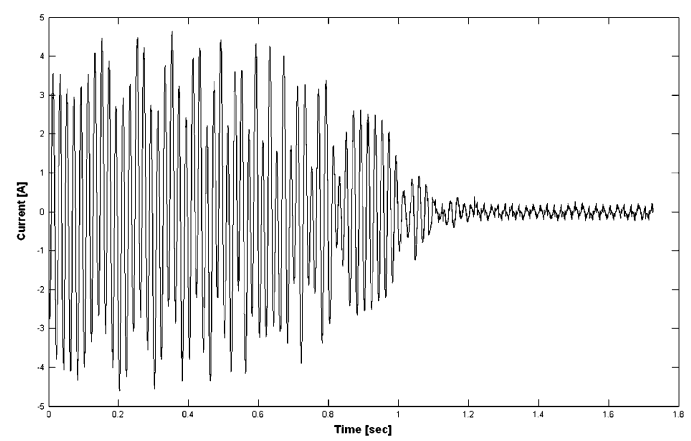

Fig. 15. Computed current versus time variation for PWM inverter-fed motor during starting.

value of $23 \mu \mathrm{F}$ and a capacitor-run value of $3 \mu \mathrm{F}$. The starting torque may reach values almost 3 times higher for the capacitor motor when compared to the inverter fed motor, for the same main supply voltage amplitude. The PWM inverter fed motor exhibits a lower starting current level (3 times lower in the analyzed case) and a much lower harmonic torque content. This is explained by the elimination of the negative sequence voltage and consequently of the unbalanced stator cage torques and pulsating torque components [1]. However, the torque/current ratio exhibits similar values for the capacitor and inverter fed motor. From the starting torque capabilities point of view, the capacitor motor performance easily overcomes the open loop inverter fed motor performance. Test data and computed data demonstrate that for high load starting conditions the capacitor motor represents the optimum solution. For low load starting conditions, the PWM inverter fed motor represents 


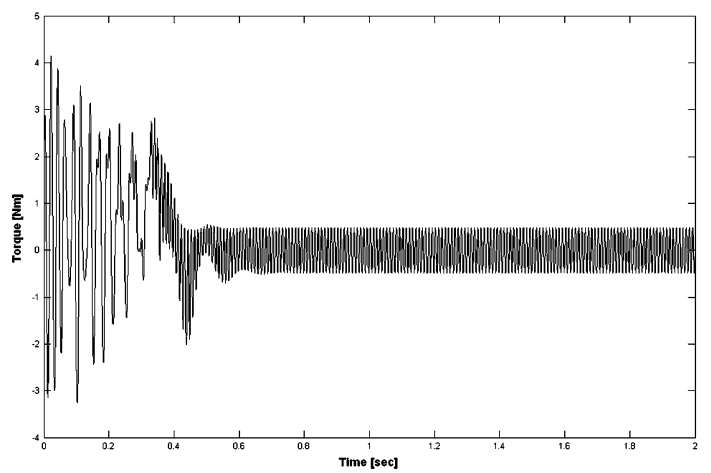

Fig. 16. Computed torque versus time variation for capacitor motor during starting $(\mathrm{C}$ start $=23 \mu \mathrm{F}, \mathrm{C}$ run $=3 \mu \mathrm{F})$.

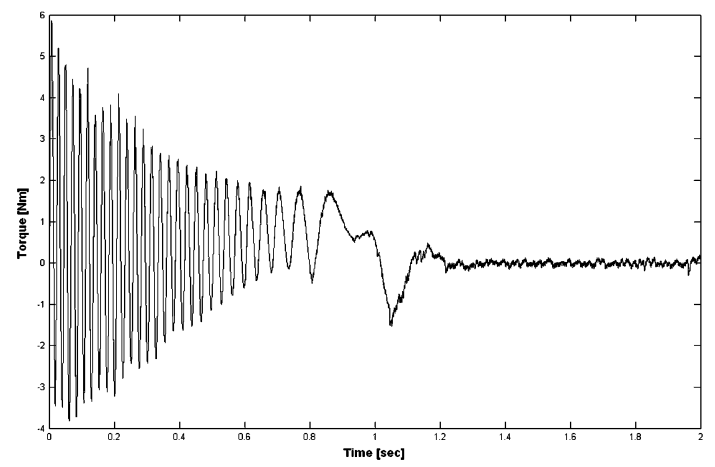

Fig. 17. Computed torque versus time variation for PWM inverter-fed motor during starting.

a reasonable alternative solution. Another drawback for the inverter fed motor solution is the longer period required for synchronization: 1.3 seconds compared to 0.45 seconds for the capacitor motor with $23 \mu \mathrm{F}$ starting capacitance.

Fig. 18 illustrates the test and computed data at synchronous operation (current versus torque) for the capacitor motor (run capacitor $=3 \mu \mathrm{F}$ ) and for the case of the PWM inverter-fed motor. Note the difference between test and computed data especially at a higher load torque level. The usage of fixed value parameters determines a good agreement between test data and computed data only for a limited load range. This is explained by the fact that the computation considered only the fundamental harmonic and has neglected the friction losses. Thus, we have employed the equivalent parameters values corresponding to the rated load and presented in the Appendix. The balanced supply voltage (i.e., no negative sequence voltage presence) is responsible for the better torque performance in the inverter fed motor case. The torque behavior at synchronous operation demonstrates a much higher stability for load variations when the motor is supplied through an inverter. The experiments showed an increased efficiency with up to $9-10 \%$ for the case of the PWM inverter supplied motor. The capacitor motor efficiency peaks at $75 \%$, while the PWM inverter fed motor runs with a maximum efficiency (motor + inverter) of $85 \%$.

The cost of the components was slightly more favorable for the capacitor motor case. All simulations have been implemented neglecting saturation and core losses. However, the motor modeling equations may be modified to include these nonlinear effects. The equivalent circuit parameters defined in the nomenclature have

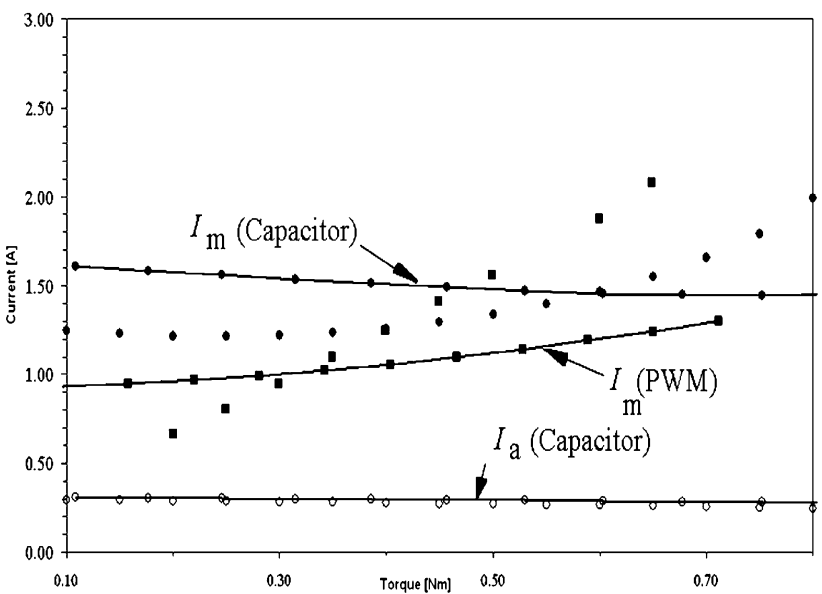

Fig. 18. Computed (line and dots) and experimental (dots) current versus load torque during synchronous operation: capacitor motor (main current full round dots and auxiliary current empty round dots) and inverter-fed motor (square dots).

been either measured or computed with the use of a specially developed program and finite element analysis.

\section{CONCLUSION}

Two starting and running methods for a single-phase permanent magnet ac motor are compared: capacitor start/run and PWM inverter fed. The torque behavior prediction for a single-phase permanent magnet ac motor can be made for asynchronous operation using the quasi steady-state plus the dynamic analysis and for synchronous operation using the steady-state analysis. Measurements and simulations demonstrate that both starting methods have advantages and drawbacks.

The electromagnetic torque versus current ratio during asynchronous operation exhibit similar values in both analyzed cases. However, for a high load torque application the capacitor motor solution is preferable while for a low load torque application the PWM inverter fed solution seems to be more advantageous.

At synchronous speed operation the PWM inverter fed solution leads to a torque vs. current ratio value that is not achievable with a capacitor motor. Torque oscillations are minimized for the PWM inverter fed motor solution as the machine always runs at synchronous speed as a 2-phase balanced motor.

\section{APPENDIX \\ MOTOR PARAMETERS}

One-phase permanent-magnet ac motor: two-pole, $220 \mathrm{~V}, 50$ $\mathrm{Hz}$ (see table).

\begin{tabular}{l|l}
\hline$R_{\mathrm{m}}=R_{\mathrm{a}}[\mathrm{ohms}]$ & 19 \\
\hline$X_{\mathrm{lm}}=X_{\mathrm{la}}[\mathrm{ohms}]$ & 4.15 \\
\hline$X_{\mathrm{md}}[\mathrm{ohms}]$ & 58.63 \\
\hline$X_{\mathrm{mq}}[\mathrm{ohms}]$ & 98.95 \\
\hline$R_{\mathrm{rd}}=R_{\mathrm{ra}}[$ ohms $]$ & 45 \\
\hline$\beta[$ main/aux turns ratio] & 1 \\
\hline$X_{\mathrm{rd}}=X_{\mathrm{r}}[$ ohms $]$ & 14.3 \\
\hline Rotor Inertia $\left[\mathrm{kgm}^{2}\right]$ & 0.0004 \\
\hline Load Inertia $\left[\mathrm{kgm}^{2}\right]$ & 0.0009 \\
\hline
\end{tabular}




\section{REFERENCES}

[1] M. Popescu, T. J. E. Miller, M. I. McGilp, G. Strappazzon, N. Trivillin, and R. Santarossa, "Line start permanent magnet motor: Single-phase starting performance analysis," in Proc. Conf. Rec. IEEE Industry Applications Soc. Annu. Meeting, vol. 4, Pittsburgh, PA, Oct. 13-18, 2002, pp. 2499-2506.

[2] T. J. E. Miller, "Single-phase permanent magnet motor analysis," IEEE Trans. Ind. Appl., vol. IA-21, no. 3, pp. 651-658, May/Jun. 1985.

[3] - "Synchronization of line-start permanent-magnet AC motors," IEEE Trans. Power App. Syst., vol. PAS-103, no. 7, pp. 1822-1828, Jul. 1984.

[4] I. Boldea, T. Dumitrescu, and S. Nasar, "Unified analysis of 1-phase AC motors having capacitors in auxiliary windings," IEEE Trans. Energy Convers., vol. 14, no. 3, pp. 577-582, Sep. 1999.

[5] C. M. Stephens, G. B. Kliman, and J. Boyd, "A line-start permanent magnet motor with gentle starting behavior," in Proc. IEEE Industry Applications Conf., vol. 1, 1998, pp. 371-379.

[6] M. A. Rahman and A. M. Osheiba, "Performance of large line-start permanent magnet synchronous motors," IEEE Trans. Energy Convers., vol. 5, no. 1, pp. 211-217, Mar. 1990.

[7] L. M. C. Mangho and R. Perryman, "Analysis and simulation of a highspeed two-phase AC drive for aerospace applications," in Proc. Inst. Elect. Eng.., Electr. Power Appl., vol. 144, Mar. 1997, pp. 149-157.

[8] D. G. Holmes and A. Kotsopoulos, "Variable speed of single and two phase induction motors using a three phase voltage source inverter," in Proc. Conf. Rec. IEEE-IAS Annu. Meeting, vol. 1, 1993, pp. 613-620.

[9] H. Huang, E. F. Fuchs, and J. C. White, "Optimization of single-phase induction motor design - Part II: The maximum efficiency and minimum cost of an optimal design," IEEE Trans. Energy Convers., vol. 3, no. 2, pp. 357-366, Jun. 1988.

[10] B. J. Chalmers, R. Magureanu, and J. Hindmarsh, "General principle for brushless synchronous machines and application in an inverter-fed drive," in Proc. Inst. Elect. Eng., vol. 119, Nov. 1972, pp. 1641-1652.

[11] E. Muljadi, E. Zhao, T.-H. Liu, and T. A. Lipo, "Adjustable AC capacitor for a single-phase induction motor," IEEE Trans. Ind. Appl., vol. 29, no. 3, pp. 479-485, May/Jun. 1993.

[12] T.-H. Liu, "A maximum torque control with a controlled capacitor for a single-phase induction motor," IEEE Trans. Ind. Electron., vol. 42, no. 1, pp. 17-24, Feb. 1995.

[13] T. A. Lettenmaier, D. W. Novotny, and T. A. Lipo, "Single-phase induction motor with an electronically controlled capacitor," IEEE Trans. Ind. Appl., vol. 27, no. 1, pp. 38-43, Jan./Feb. 1991.

[14] T. J. E. Miller, M. Popescu, C. Cossar, M. I. McGilp, and J. A. Walker, "Calculating the interior permanent-magnet motor," in Proc. Conf. Rec. IEEE Int. Electrical Machines Drives Conf., vol. 3, Madison, WI, 2003.

Mircea Popescu (S'98-M'99-SM'04) was born in Bucharest, Romania, in 1959. He received the B.Sc. degree in statistics and economics from the Academy of Economical Studies, Bucharest, Romania, in 1992, and the M.Eng. and $\mathrm{Ph} . \mathrm{D}$. degrees in electrical engineering from the University "Politehnica" Bucharest, Bucharest, Romania, in 1984 and 1999, respectively.

From 1984 to 1986 , he was involved in dc drives design and quality testing at "Electrothenica" S.A. Bucharest. From 1986 to 1997, he worked in industrial research and development at the Research Institute for Electrical Machines (ICPE-ME), Bucharest, Romania, as a Project Manager. From 1991 to 1997, he cooperated as a Visiting Assistant Professor with the Electrical Engineering Faculty, Electrical Drives and Machines Department, University "Politehnica" Bucharest. From 1997 to 2000, he was a Research Scientist with the Electromechanics Laboratory, Helsinki University of Technology, Espoo, Finland. He is currently with the SPEED Laboratory, Glasgow University, Glasgow, U.K., as a Research Associate.
T. J. E. Miller (M'74-SM'82-F'96), is a native of Wigan, U.K. He received the B.Sc. degree from the University of Glasgow, Glasgow, U.K., and the Ph.D. degree from the University of Leeds, Leeds, U.K.

$\mathrm{He}$ is Professor of Electrical Power Engineering and founder and Director of the SPEED Consortium at the University of Glasgow, Glasgow, U.K. He is the author of over 100 publications in the fields of motors, drives, power systems, and power electronics, including seven books. From 1979 to 1986, he was an Electrical Engineer and Program Manager at GE Research and Development, Schenectady, NY, and his industrial experience includes periods with GEC (UK), British Gas, International Research and Development, and a student apprenticeship with Tube Investments Ltd.

Prof. Miller is a Fellow of the Institution of Electrical Engineers, U.K.

Malcolm McGilp was born in Helensburgh, U.K., in 1965. He received the B.Eng. (Hons.) degree in electronic systems and microcomputer engineering from the University of Glasgow, Glasgow, U.K., in 1987.

Since graduating, he has been with the SPEED Laboratory, University of Glasgow, first as a Research Assistant from 1987 to 1996 and as a Research Associate since then. He is responsible for the software architecture of the SPEED motor design software and has developed the interface and user facilities which allow it to be easy to learn and integrate with other PC-based software.

Giovanni Strappazzon graduated from the Faculty of Electrical Engineering, Padua University, Padua, Italy, in 1998, on the basis of a dissertation about analysis of small induction motors for the optimization in the design of electrical motors.

He worked shortly for a factory that makes small synchronous motors mainly for aquarium pumps. Since the beginning of 2001, he has been a Researcher on innovative motors for ACC Compressors, Pordenone, Italy.

Mr. Strappazzon won an award as a Researcher in the Department of Electrical Engineering, Padua University, in 1999.

Nicola Trivillin was born in Pordenone, Italy, in 1970. He received the "Laurea" degree in electrical engineering from Padua University, Padua, Italy, in 1995, with a thesis on finite-element analysis of a single-phase induction motor with auxiliary phase.

He joined the R\&D Department of ACC Compressors, Pordenone, Italy, as an Electric Motor Specialist, and is currently Manager of the Electrical Competence Center.

Roberto Santarossa was born in Pordenone, Italy, in 1969. He received the degree in electrical engineering from the University of Padua, Padua, Italy, in 1996, with a thesis about voltage stability of a large electric power system.

Since 1997, he has been with ACC Compressors, Pordenone, Italy, where he is currently an Electric Motor Designer, dealing with design and development of fractional horsepower motors. 